\section{Influence of diabetes on macular thickness measured using optical coherence tomography: the Singapore Indian Eye Study}

CCA Sng ${ }^{1,2}$, CY Cheung ${ }^{1}$, RE Man ${ }^{1}$, W Wong', R Lavanya', P Mitchell ${ }^{3}$, T Aung ${ }^{1,2}$ and TY Wong ${ }^{1,2}$
${ }^{1}$ Singapore Eye Research Institute and Singapore National Eye Centre, Singapore, Singapore

${ }^{2}$ Department of Ophthalmology, Yong Loo Lin School of Medicine, National University Health System, Singapore,

Singapore

${ }^{3}$ Department of Ophthalmology, University of Sydney, Sydney, New South Wales, Australia

Correspondence: TY Wong, Singapore Eye Research Institute, 11 Third Hospital Avenue, Singapore 168751 Tel: +6563224584

Fax: + 6563231903

E-mail: ophwty@nus.edu.sg

Received: 17 October 2011 Accepted in revised form: 27 December 2011

Published online:

17 February 2012

\begin{abstract}
Purpose To determine the influence of diabetes, diabetic retinopathy (DR), and other factors on macular thickness, measured using optical coherence tomography (OCT), in a population-based sample.

Methods Data from the population-based Singapore Indian Eye Study were analyzed. We measured macular thickness using Stratus OCT Fast Macular Thickness scan protocol in 228 participants with diabetes mellitus (including 167 without DR, 44 with mild DR, 17 with moderate or severe DR) and 72 nondiabetic controls without macular oedema or other macular lesions. Analysis was done on right eyes.

Results The mean age of participants was $60.1 \pm 10.1$ years, with $53.8 \%$ men. Macular thickness measurements did not differ significantly between diabetic participants with no or mild DR and non-diabetic participants. Diabetic participants with moderate or severe DR had greater foveal and temporal outer macula thickness compared with those with no or mild DR $(P=0.003)$. In a multivariate linear regression model, older age $(P=0.009)$, male gender $(P=0.005)$, and lower spherical equivalent $(P=0.001)$ were other factors associated with greater foveal thickness in all participants after controlling for body mass index, glycosylated haemoglobin, total cholesterol, and mean systolic blood pressure. Conclusion This population-based study showed that diabetic participants with moderate or severe DR had thicker foveal
\end{abstract}

measurements, even in the absence of diabetic macula oedema, than non-diabetic controls. Other factors that influenced macular thickness measurements were age, gender, and spherical equivalent. These data may aid the interpretation of OCT findings in persons with diabetes and DR.

Eye (2012) 26, 690-698; doi:10.1038/eye.2012.11; published online 17 February 2012

Keywords: optical coherence tomography; diabetic retinopathy; macula

\section{Introduction}

Optical coherence tomography (OCT) is a noninvasive imaging modality now extensively used to measure retinal thickness. ${ }^{1,2}$ Despite widespread clinical use, there are only few studies from the general population on the distributions and correlations of OCT-measured retinal thickness, mostly in white ethnic groups. ${ }^{3-5}$ There are also few studies on normative OCT measures in major patient groups, such as persons with diabetes. ${ }^{6-8}$ Normative data in general populations are essential to allow pathological changes to be compared, identified, and characterized. It is particularly important to establish normative values in persons with diabetes with nearly 400 million such individuals worldwide by $2030 .^{9}$

Previous studies on macular thickness measurements in persons with diabetes, obtained using OCT and other instruments such as the retinal thickness analyzer, have reported variable findings. ${ }^{6-8,10-19}$ Biallosterki et $a l^{7}$ 
reported that thinner pericentral macular thickness in patients with minimal diabetic retinopathy (DR) compared with controls, and hypothesized that this was due to neuronal loss in the earliest stage of DR. ${ }^{20}$ In contrast, Lattanzio et $a l^{12}$ found that the macular thickness in subjects with diabetes without DR was thicker (by more than $40 \mu \mathrm{m}$ ) than that in non-diabetic controls. Others have reported no difference in macular thickness between subjects with diabetes with minimal or no DR and non-diabetic controls. ${ }^{18}$ Importantly, all previous studies on macular thickness in diabetic persons recruited the participants from hospitals and universities, hence were limited by potential selection bias (eg, patients with better (or worse) diabetes control may have been more likely to be included) ${ }^{6-8,10-19}$ At present, there are no population-based published data on the macular thickness in diabetic individuals with and without DR, and how macular thickness parameters compare with normal non-diabetic controls.

In this study, we described and compared macular thickness using Stratus OCT (Carl Zeiss Meditec, Dublin, CA, USA) in persons with or without diabetes in a population-based study in Asian Indians, and identified factors that affected macular thickness measurements.

\section{Methods}

\section{Subjects}

We analyzed data from the Singapore Indian Eye Study, a population-based cross-sectional survey of ethnic Indians aged 40-80 years living in the south-western part of Singapore. The subjects were selected using an agestratified (by 10-year age group) random sampling method, from a computer-generated list provided by the Ministry of Health, Singapore. The methodology and objectives of the study population have been reported in detail elsewhere. $^{21,22}$ Of the eligible 4497 participants, 3400 (response rate $75.6 \%$ ) participated in the study, conducted from May 2007 through December 2009. Participants underwent a standardized interview, systemic and ocular examination, and laboratory investigations.

As part of the study between June 2008 and April 2009, we recruited 283 participants with diabetes mellitus and 88 non-diabetic controls for OCT measurement. OCT scans were obtained for all participants with diabetes and selected non-diabetic controls. Of the 371 participants, we excluded 38 participants with coexisting macular pathology (including any evidence of diabetic macular oedema, epiretinal membrane formation, or myopic maculopathy) and a history or signs of previous retinal laser treatment. In all, 33 participants who did not have fundal photographs or had poor quality OCT scans of signal strength $<6$ were further excluded. This left 300 (228 subjects with diabetes and 72 non-diabetic controls) in the final analysis.

\section{OCT}

OCT scanning was performed by trained technicians using Stratus OCT (Carl Zeiss Meditec). Macular thickness measurements were obtained from the right eye of the participants after pupil dilatation, using tropicamide $1 \%$ and phenylephrine hyprochloride $2.5 \%$. The Fast Macular Thickness scan protocol was used, which acquires six 6-mm linear scans oriented $30^{\circ}$ apart in a radial spoke-like pattern in a continuous automated sequence. Each of the six linear scans is composed of 128 equally spaced transverse axial scans. The reproducibility of retinal thickness measurements using the Fast Macular Thickness mapping protocol of Stratus OCT is high in normal eyes. ${ }^{23}$ The Stratus OCT software generated a topographical map of the macula, which is composed of nine sectorial thickness measurements in three concentric circles with diameters of 1,3 and $6 \mathrm{~mm}$, as defined by the Early Treatment of Diabetic Retinopathy Study (ETDRS). ${ }^{24}$ The inner and outer rings were segmented into quadrants. Foveal thickness was defined as the average thickness in the central $1 \mathrm{~mm}$ diameter, according to the ETDRS layout. ${ }^{24}$ Only the OCT scans with signal strength $\geq 6$ were included in this analysis.

\section{Definition of diabetes and DR}

Non-fasting venous blood samples were analyzed at the National University Hospital Reference Laboratory for biochemical testing of glycosylated haemoglobin $\left(\mathrm{HbA} 1_{\mathrm{C}}\right)$ and glucose. Diabetes mellitus was identified from non-fasting plasma glucose $\geq 11.1 \mathrm{mmol} / \mathrm{l}$, self-reported use of diabetic medication, or physician-diagnosed diabetes.

A digital retinal camera (Canon CR-DGi with a 20 Dioptre SLR backing, Canon, Tokyo, Japan) was used to perform retinal photography after pupil dilation. Early Treatment for Diabetic Retinopathy Study (ETDRS) standard field 1 (centred on the optic disc) and ETDRS standard field 2 (centred on the fovea) retinal images were taken. ${ }^{25}$ Trained graders at the Centre for Vision Australia, University of Sydney, masked to the participant characteristics, evaluated the retinal photographs for the presence and severity of DR. Any retinopathy was defined as a severity score of level 15 and above, according to a scale graded using the ETDRS adaptation of the modified Airlie House Classification System corresponding to the presence of any of the following lesions: microaneurysms, haemorrhages, cotton wool spots, intraretinal microvascular 
abnormalities, hard exudates, venous beading, and new vessels. $^{26,27}$ A severity score of up to level 35 was considered as mild DR, from level 36 to 43 as moderate DR, and above 47 as severe DR. Among the 228 diabetic participants, no DR was seen in 167 participants, mild DR was present in 44 participants, moderate or severe DR was present in 17 participants. We excluded 38 participants because they had signs of macular oedema or other maculopathies.

\section{Refraction}

Subjective refraction and distance best-corrected visual acuity in logarithm of the minimum angle of resolution (Log MAR) scores were measured by trained and certified study optometrists. ${ }^{28}$ The spherical equivalent (SE) was determined by:

$$
\mathrm{SE}=\mathrm{S}+\mathrm{C} / 2
$$

where $S$ was the spherical power, and $C$ was the cylindrical power.

\section{Measurement of other variables}

Prior to OCT imaging, detailed interviewer-administered questionnaires that collected relevant socio-demographic data (including alcohol intake, smoking, and a standardized diabetes questionnaire) and medical history were administered. The age of each participant was recorded at the time of clinic examination, when OCT imaging was performed. We evaluated the systolic and diastolic blood pressure (BP) with a digital automatic BP monitor (Dinamap model Pro 100V2; Critericon,

Norderstedt, Germany), after the participants were seated for 5 minutes with legs uncrossed. A total of three measurements was taken, and the average of the two closest BP readings were taken as each participant's BP. The $\mathrm{MABP}$ (mean arterial BP) was calculated by this equation:

$$
\mathrm{MABP}=1 / 3(\text { systolic } \mathrm{BP}+2 \times \text { diastolic } \mathrm{BP}) .
$$

Body mass index (BMI) was calculated as the weight (in kilograms) divided by body height (in metres) squared. Biochemical analysis of random blood samples was performed on the day of the clinic examination at the National University Hospital Reference Laboratory, for total cholesterol, high-density lipoprotein cholesterol, and low-density lipoprotein cholesterol.

\section{Statistical analysis}

We compared the demographics between diabetic participants and controls using the chi-square test or one-way analysis of variance as appropriate. Analysis of covariance was used to compare OCT parameters between these groups: (1) diabetic participants without DR; (2) diabetic participants with mild DR; (3) diabetic participants with moderate or severe DR, adjusting for age, $\mathrm{HbA} 1_{\mathrm{C}}$, systolic $\mathrm{BP}$, diabetes duration, total cholesterol, low-density lipoprotein cholesterol, and BMI. Multivariable linear regression models were constructed with foveal thickness and total macular volume as the dependent variables, and adjusting for age, gender, BMI, $\mathrm{HbA} 1_{\mathrm{C}}$, total cholesterol, SE, systolic $\mathrm{BP}$, and retinopathy (with participants without diabetes as the reference). This was repeated for diabetic subjects alone, after further adjustment for duration of diabetes and the presence of retinopathy (with diabetic participants with no DR as the reference). $P$-values $<0.05$ were considered to be statistically significant. All analyses were performed with STATA version 11 (StataCorp. LP, College Station, TX, USA).

\section{Results}

Baseline characteristics of the participants are summarized in Table 1 . There were significant differences in age $(P<0.001), \mathrm{HbA}_{\mathrm{c}}(P<0.001)$, systolic BP $(P=0.003)$, total cholesterol $(P<0.001)$, low-density lipoprotein cholesterol $(P<0.001)$, and BMI $(P=0.036)$ between the four groups. Diabetic participants with moderate or severe DR had a longer duration of diabetes compared with those with mild or no DR $(P<0.001)$.

Diabetic participants with moderate or severe DR had greater foveal thickness (213.36, 95\% confidence interval (CI) $199.03,227.70 \mu \mathrm{m})$ and temporal outer macula thickness $(218.93,95 \%$ CI 209.18, $228.67 \mu \mathrm{m})$ compared with those with mild DR (194.98, 95\% CI 186.62, 203.34, and $215.72,95 \%$ CI 210.19, $221.25 \mu \mathrm{m}$, respectively) and no DR (187.51, 95\% CI 183.21, 191.80, and 209.21, 95\% CI $206.38,212.03 \mu \mathrm{m}$, respectively) $(P=0.003$ and $P=0.045$, respectively) (Table 2, Figure 1). The mean and SD of macular thickness in participants with diabetes are shown in Figure 2.

In the multivariable linear regression model of foveal thickness in all participants and in participants with diabetes, older age $(P=0.009$ and $P=0.014$, respectively), male gender $(P=0.005$ and $P=0.007$, respectively), lower SE $(P=0.001$ and $P=0.019$, respectively), and the presence of moderate or severe DR $(P=0.001$ and $P<0.001$, respectively) were associated with increased foveal thickness. (Table 3A). In the multivariable linear regression model of macular volume in all participants and in participants with diabetes, older age $(P<0.001$ and $P=0.001$, respectively), male gender $(P=0.003$ and $P=0.037$, respectively), greater SE $(P=0.015$ and $P=0.007$, respectively), and the presence of moderate or severe DR $(P=0.015$ and $P=0.041$, respectively) were 
Table 1 Demographic characteristics of participants

\begin{tabular}{|c|c|c|c|c|c|}
\hline & \multirow{2}{*}{$\begin{array}{l}\text { Non-Diabetic Controls } \\
(\mathrm{n}=72)\end{array}$} & \multicolumn{3}{|c|}{ Diabetes } & \multirow[t]{2}{*}{ P-value ${ }^{\mathrm{a}}$} \\
\hline & & $\begin{array}{l}\text { No retinopathy } \\
\quad(\mathrm{n}=167)\end{array}$ & $\begin{array}{l}\text { Minimal/mild } \\
D R(\mathrm{n}=44)\end{array}$ & $\begin{array}{c}\text { Moderate/severe } \\
D R(\mathrm{n}=17)\end{array}$ & \\
\hline Age, years & $54.2(8.2)$ & $60.8(9.9)$ & $60.3(9.9)$ & $59.4(7.9)$ & $<0.001$ \\
\hline Men, \% & $39(54.2)$ & 89 (53.3) & $27(61.4)$ & $9(52.9)$ & 0.813 \\
\hline Mean arterial blood pressure, $\mathrm{mm} \mathrm{Hg}$ & $97.07(11.63)$ & $96.22(9.34)$ & $98.16(14.36)$ & $99.16(2.49)$ & 0.569 \\
\hline Spherical equivalent (right eye) & $-0.16(1.88)$ & $-0.31(2.20)$ & $0.27(1.13)$ & $0.30(2.43)$ & 0.291 \\
\hline $\mathrm{HbA1c}, \%$ & $5.96(0.57)$ & $7.29(1.21)$ & $7.61(1.60)$ & $8.29(2.00)$ & $<0.001$ \\
\hline Diabetes duration, year & - & $8.23(7.65)$ & $12.34(8.23)$ & $15.06(9.85)$ & $<0.001$ \\
\hline Systolic blood pressure, $\mathrm{mm} \mathrm{Hg}$ & $131.83(17.97)$ & $136.87(16.54)$ & $143.08(21.68)$ & $143.94(18.23)$ & 0.003 \\
\hline Total cholesterol, $\mathrm{mmol} / \mathrm{l}$ & $5.30(0.92)$ & $4.61(0.95)$ & $4.51(1.102)$ & $4.47(1.36)$ & $<0.001$ \\
\hline LDL cholesterol, mmol/1 & $3.55(0.85)$ & $2.87(0.81)$ & $2.75(0.75)$ & $2.70(1.04)$ & $<0.001$ \\
\hline HDL cholesterol, mmol/1 & $1.09(0.32)$ & $1.03(0.31)$ & $1.01(0.32)$ & $0.98(0.25)$ & 0.404 \\
\hline Body mass index, $\mathrm{kg} / \mathrm{m}^{2}$ & $25.45(5.72)$ & $27.46(5.22)$ & $27.88(5.74)$ & $26.43(3.38)$ & 0.036 \\
\hline Smoking status, yes vs no & 10 (13.9) & $17(10.2)$ & $7(15.9)$ & $3(17.6)$ & 0.606 \\
\hline
\end{tabular}

Data is mean (SD) or count (\%).

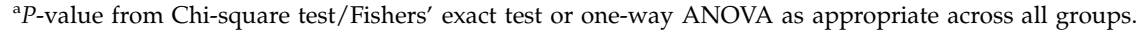

Table 2 Comparison between Diabetic Participants without Diabetic Retinopathy (DR) and severity of Diabetic Retinopathy

\begin{tabular}{lcccc}
\hline Macular measurements & \multicolumn{3}{c}{ Diabetes } & \\
\cline { 2 - 5 } & No retinopathy $(\mathrm{n}=167)$ & Minimal $/$ mild DR $(\mathrm{n}=44)$ & Moderate/severe DR $(\mathrm{n}=17)$ \\
\hline Foveal thickness, $\mu \mathrm{m}$ & $187.51(183.21,191.80)$ & $194.98(186.62,203.34)$ & $213.36(199.03,227.70)$ & 0.003 \\
Temporal inner macula, $\mu \mathrm{m}$ & $249.30(245.49,253.12)$ & $254.23(246.75,261.70)$ & $260.31(247.15,273.48)$ & 0.212 \\
Superior inner macula, $\mu \mathrm{m}$ & $259.21(255.83,262.59)$ & $264.09(257.47,270.72)$ & $259.56(247.89,271.23)$ & 0.437 \\
Nasal inner macula, $\mu \mathrm{m}$ & $259.29(255.43,263.16)$ & $264.80(257.22,272.37)$ & $258.42(245.07,271.77)$ & 0.425 \\
Inferior inner macula, $\mu \mathrm{m}$ & $259.52(255.84,263.20)$ & $265.64(258.43,272.85)$ & $258.42(245.72,271.13)$ & 0.309 \\
Temporal outer macula, $\mu \mathrm{m}$ & $209.21(206.38,212.03)$ & $215.72(210.19,221.25)$ & $218.93(209.18,228.67)$ & 0.045 \\
Superior outer macula, $\mu \mathrm{m}$ & $225.22(222.40,228.06)$ & $231.90(226.35,237.45)$ & $227.52(217.74,237.29)$ & 0.119 \\
Nasal outer macula, $\mu \mathrm{m}$ & $246.29(243.27,249.30)$ & $248.64(242.73,254.56)$ & $247.57(237.14,257.99)$ & 0.788 \\
Inferior outer macula, $\mu \mathrm{m}$ & $221.19(218.50,223.88)$ & $226.08(220.82,231.35)$ & $224.25(214.97,233.52)$ & 0.267 \\
Total macular volume, $\mathrm{mm}{ }^{3}$ & $6.56(6.48,6.63)$ & $6.70(6.56,6.85)$ & $6.67(6.41,6.93)$ & 0.211 \\
\hline
\end{tabular}

Data are adjusted mean $(95 \% \mathrm{CI})$.

aP-value from ANCOVA of means comparison between groups (adjusting for age, hba1c, systolic blood pressure, diabetes duration, total cholesterol, low density lipoprotein cholesterol, and body mass index).

associated with increased macular volume (Table 3B). The presence of diabetes and mild or no DR did not significantly affect foveal thickness or total macular volume measurements compared with participants without diabetes. Among participants with diabetes, the duration of diabetes, $\mathrm{HbA} 1_{\mathrm{C}}$, and the presence of mild DR did not significantly affect foveal thickness or total macular volume measurements compared with those without DR (Table 3). All models were also adjusted for BMI, total cholesterol, and systolic BP.

\section{Discussion}

In this population-based study, we found that persons with diabetes with moderate or severe DR had increased foveal and temporal outer macula thickness compared with those with no or mild DR and persons without

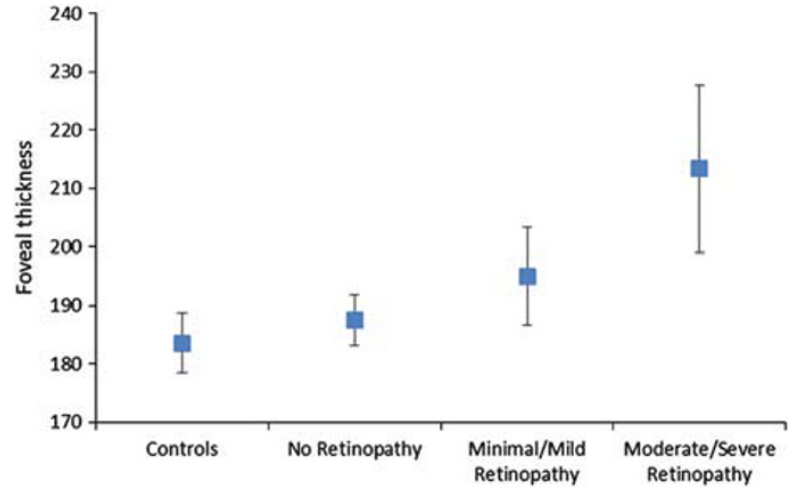

Figure 1 Boxplots of foveal thickness in the study participants.

diabetes. Age, gender, and SE were other factors that significantly affected macular volume and foveal thickness. However, there were no significant differences 


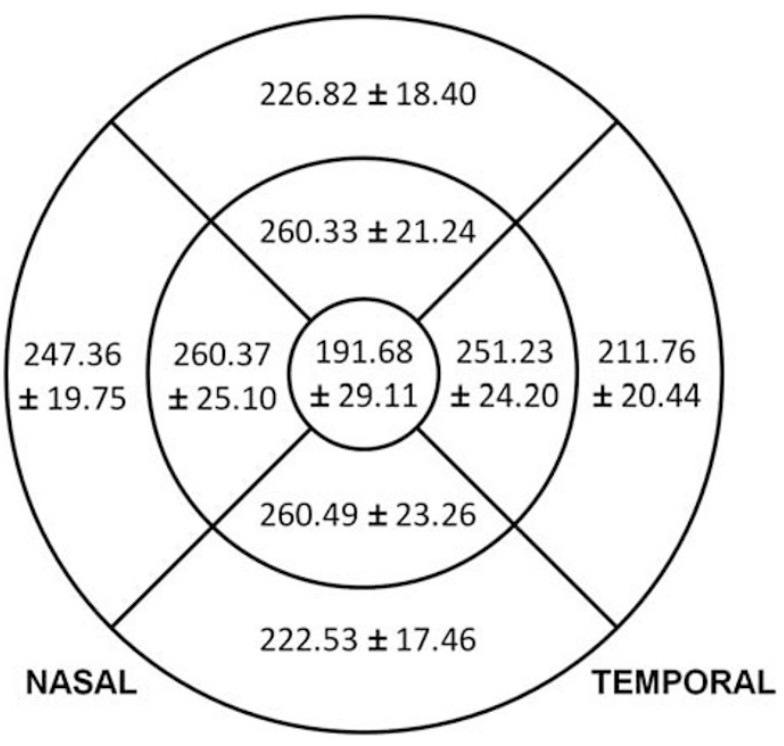

Figure 2 Mean and standard deviations of macular thickness $(\mu \mathrm{m})$ by sector in the right eye of each subject in 228 diabetic participants from the Singapore Indian Eye Study, with optical coherence tomography using the Fast Macular Thickness scan protocol. in macular thickness measurements between diabetic persons with no or mild DR and persons without diabetes. Furthermore, among participants with diabetes, the duration of diabetes and $\mathrm{HbA} 1_{C}$ did not significantly affect macular thickness measurements.

Our results provide new population-based data on the macular thickness measurements in persons with diabetes, which have not been previously reported. Our finding that the severity of DR significantly affects macular thickness measurements even in the absence of diabetic macular oedema is also novel. We showed that diabetic individuals with moderate or severe DR had increased fovea and temporal outer macular thickness compared with those who had no DR and non-diabetic individuals, though a few earlier studies have described a generalized increase in macular thickness in persons with diabetes. ${ }^{12,16,29}$ In contrast, there were no significant differences in fovea thickness and macular volume measurements between diabetic persons with mild or no DR and non-diabetic persons. This may be explained by an alteration of the blood-retinal barrier in moderate and severe $\mathrm{DR}^{30}$ which may facilitate an increase in the

Table 3 Multivariable linear regressions of Foveal Thickness and Macular Volume

\begin{tabular}{|c|c|c|c|c|}
\hline \multirow[t]{2}{*}{ Factors } & \multicolumn{2}{|c|}{ All persons $(\mathrm{n}=300)$} & \multicolumn{2}{|c|}{ Persons with diabetes $(\mathrm{n}=228)$} \\
\hline & Mean difference $(95 \% \mathrm{CI})^{\mathrm{a}}$ & P-value & Mean difference $(95 \% C I)^{\mathrm{a}}$ & P-value \\
\hline \multicolumn{5}{|c|}{ A. Multiple linear regression of Foveal thickness } \\
\hline Age, per year & $0.46(0.12,0.81)$ & 0.009 & $0.60(0.12,1.08)$ & 0.014 \\
\hline Gender, female vs male & $-8.82(-14.94,-2.70)$ & 0.005 & $-10.62(-18.30,-2.30)$ & 0.007 \\
\hline BMI & $-0.20(-0.79,0.39)$ & 0.503 & $-0.16(-0.91,0.58)$ & 0.672 \\
\hline Total cholesterol & $-1.90(-5.17,1.38)$ & 0.255 & $-2.74(-6.82,1.33)$ & 0.185 \\
\hline Spherical equivalent & $-2.61(-4.10,-1.12)$ & 0.001 & $-2.21(-4.05,-0.38)$ & 0.019 \\
\hline Diabetes duration & - & - & $-0.20(-0.73,0.32)$ & 0.443 \\
\hline Systolic blood pressure & $0.09(-0.08,0.26)$ & 0.279 & $0.15(-0.06,0.36)$ & 0.152 \\
\hline \multicolumn{5}{|l|}{ Retinopathy } \\
\hline Non-diabetics and no retinopathy & Reference & & - & - \\
\hline Diabetics with no retinopathy & $-2.43(-11.16,6.29)$ & 0.584 & Reference & \\
\hline Diabetics with minimal/mild & $5.52(-5.84,16.87)$ & 0.340 & $8.01(-1.55,17.56)$ & 0.100 \\
\hline \multicolumn{5}{|c|}{ B. Multiple linear regression of total macular volume } \\
\hline Age, per year & $-0.01(-0.02,-0.01)$ & $<0.001$ & $-0.01(-0.02,-0.01)$ & 0.001 \\
\hline Gender, female vs male & $-0.16(-0.27,-0.05)$ & 0.003 & $-0.14(-0.28,-0.01)$ & 0.037 \\
\hline BMI & $-0.01(-0.02,0.003)$ & 0.176 & $-0.01(-0.02,0.003)$ & 0.126 \\
\hline $\mathrm{HbA} 1_{\mathrm{C}}$ & $0.03(-0.02,0.07)$ & 0.258 & $0.03(-0.02,0.08)$ & 0.304 \\
\hline Total cholesterol & $-0.007(-0.063,0.058)$ & 0.810 & $-0.03(-0.10,0.04)$ & 0.419 \\
\hline Spherical equivalent & $0.03(0.01,0.06)$ & 0.015 & $0.04(0.01,0.07)$ & 0.007 \\
\hline Diabetes duration & - & - & $0.004(-0.005,0.013)$ & 0.414 \\
\hline Systolic blood pressure & $-0.001(-0.004,0.002)$ & 0.643 & $0.0001(-0.0035,0.0038)$ & 0.941 \\
\hline \multicolumn{5}{|l|}{ Retinopathy } \\
\hline Non-diabetics and no retinopathy & Reference & & - & - \\
\hline Diabetics with no retinopathy & $0.02(-0.13,0.17)$ & 0.780 & Reference & \\
\hline Diabetics with minimal/mild & $0.16(-0.03,0.36)$ & 0.100 & $0.12(-0.05,0.29)$ & 0.156 \\
\hline Diabetics with moderate/severe & $0.35(0.07,0.63)$ & 0.015 & $0.28(0.01,0.55)$ & 0.041 \\
\hline
\end{tabular}

Abbreviations: $\mathrm{CI}$, confidence interval; $\mathrm{DR}$, diabetic retinopathy; $\mathrm{HbA1} 1_{\mathrm{C}}$ glycosylated hemoglobin.

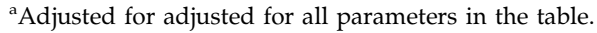


vascular permeability of perifoveal and macular capillaries. Another possible mechanism for increased foveal thickness in persons with moderate or severe DR is interstitial oedema secondary to perifoveal capillary loss, which has been found to occur in the course of DR. ${ }^{31}$ Hudson $e a^{32}$ have reported that macular capillary blood flow was lower in areas of diabetic macular oedema and this reduction was more evident in the temporal compared with the nasal macula $(P=0.01)$, which is consistent with our finding that the temporal outer macula thickness was increased in persons with moderate or severe DR. These vascular changes may be related to the severity of DR even in the absence of diabetic macular oedema. Additional studies are required to verify these hypotheses. A meta-analysis evaluating the diagnostic accuracy of OCT for detecting macular oedema in people with DR found that OCT can detect macular thickening earlier than clinical examination, but many such cases did not progress to clinically detectable macular oedema and require photocoagulation. ${ }^{33}$

The findings of previous studies on macular thickness measurements in diabetic individuals were inconsistent, with some studies reporting a decreased ${ }^{6,7,19,34}$ or increased $^{12,16,29}$ macular thickness, whereas other studies reported similar macular thickness measurements compared with non-diabetic controls. ${ }^{8,18}$ There are a few possible reasons for these discrepancies. Firstly, some studies included persons with diabetic macular oedema, ${ }^{11,17}$ whereas others only recruited diabetic individuals with no or minimal DR. ${ }^{15,18}$ Secondly, earlier studies were hospital- or university-based, hence were subject to selection bias, ${ }^{6-8,10-19}$ which are minimized in a population-based study. Thirdly, most of the previous studies did not adjust for age, gender, ethnicity or refractive error, ${ }^{6,7,11,29}$ which are possible confounders for retinal thickness measurements. Lastly, macular thickness was assessed by instruments other than the OCT in some of the earlier studies, such as the retinal thickness analyzer, and these imaging modalities may not be comparable to Stratus OCT. ${ }^{10,29,35-37}$

We identified age, gender, and SE as factors that significantly affected macular measurements using Stratus OCT, which is consistent with the results of previous studies. ${ }^{10,13,18,38-41}$ However, our results also indicate that more myopic individuals have an increased foveal thickness but reduced macular volume, which substantiate earlier reports. ${ }^{40,41}$ Lam et al ${ }^{40}$ hypothesized that the thicker fovea could be a sign of early vitreoretinal traction in highly myopic eyes. Previous studies reported that women have thinner macular measurements, ${ }^{13,30,38,39}$ which is consistent with our results. This may explain why certain macular conditions, such as macular hole, occur more frequently in women. We showed that older age is associated with increased OCT measurements of the fovea. This supports the findings of Kashani et $a l^{18}$ and may be caused by the presence of interstitial oedema from capillary dropout with age, Angiographic evidence is required to substantiate this hypothesis. However, our results also indicate that although foveal thickness is greater with increasing age, macular volume is reduced. This adds to the growing evidence that the macular thinning that occurs with aging is non-uniform. ${ }^{42}$ In our study, the duration of diabetes and $\mathrm{HbA} 1_{\mathrm{C}}$ levels did not significantly affect macular thickness measurements. In contrast, previous studies have reported increased macular thickness with higher $\mathrm{HbA} 1_{\mathrm{C}}$ levels, ${ }^{43,44}$ whereas a longer duration of diabetes was associated with thinner macula measurements in the absence of macula oedema. ${ }^{45,46}$ However, these studies were not population-based, hence were susceptible to selection bias. In addition, the level of $\mathrm{HbA} 1_{\mathrm{C}}$ and the duration of diabetes are likely confounded by the severity of DR, which was not adjusted for in these earlier studies.

Our results have research implications and are also clinically significant. First, our data support previous studies, which showed that mild macular thickening on OCT may not correspond to overt oedema recognized by slit lamp biomicrosopy. ${ }^{12,47}$ This has been termed 'subclinical macular oedema', ${ }^{48,49}$ and has been described in up to $25 \%$ of eyes without clinically significant macular oedema. ${ }^{47}$ Bhavsar and Subramaniam ${ }^{48}$ found that a significant number of patients with subclinical macular oedema ultimately progress to clinically significant macular oedema compared with controls, with a $15 \%$ increase in the odds of progression with each $10 \mu \mathrm{m}$ increase in central subfield macular thickness (OR 1.15, CI 1.03-1.28; $P=0.01$ ). It may therefore be important to monitor such diabetic individuals more closely so that potential vision-threatening macular oedema can be detected earlier. Second, it is well known that diabetes may also accelerate retinal neuronal cell death, ${ }^{50}$ resulting in macular atrophy. However, this is inconsistent with our results, which have shown an increase in macular thickness measurements in persons with diabetes. Further studies using spectral-domain OCT to measure the specific retinal layers are necessary to verify this hypothesis. Third, our data provide normative values of macular thickness in diabetic eyes. Such normative values are important in the interpretation of previous clinical trials evaluating DR and diabetic macular oedema using Stratus OCT, and may also be applicable in designing future research questions using spectral-domain OCT. Our results that diabetic persons with moderate or severe DR have an increased foveal thickness, even in the absence of macular oedema, should be taken into consideration when determining the upper limits of normal for eligibility into such trials. ${ }^{14}$ These findings 
further provide insights into the pathogenesis of early changes in DR. Our results have also confirmed that it is essential to adjust for age, gender, and SE when conducting analyses of OCT measurements, whereas most earlier studies assessing macular thickness values in persons with diabetes did not adjust for these confounding factors. $6,7,11,29$

The main strength of our study is the population-based design, which minimizes the selection bias inherent in previous hospital- and university-based studies. ${ }^{6-8,10-19}$ Other strengths include detailed information on the severity of DR and possible confounders, such as BP and SE, and the use of a standardized diabetes questionnaire. However, some limitations should be considered in the interpretation of our findings. We did not distinguish between type 1 or type 2 diabetes, which vary in pathophysiology and treatment, hence might also vary in macular thickness measurements. An additional limitation of our study is the lack of data pertaining to the diagnosis of glaucoma in the participants, which is a possible confounder in the assessment of macular thickness. ${ }^{51,52}$

In summary, our results provide population-based data that would be useful in the interpretation of macular thickness values in persons with diabetes. We have shown that macular thickness measurements are increased in moderate or severe DR even when diabetic macular oedema is absent. Additional studies using spectral-domain OCT are indicated to extend these results, and more advanced retinal segmentation methods should be used to investigate whether specific retinal layers are preferentially affected by diabetes.

Summary

What was known before

- Despite widespread clinical use of optical coherence tomography (OCT), there are only few studies from the general population on the distributions and correlations of OCT-measured retinal thickness, mostly in white ethnic groups.

- At present, there are no population-based published data on the macular thickness in diabetic individuals with and without diabetic retinopathy (DR), and how macular thickness parameters compare with normal non-diabetic controls.

What this study adds

- Our results provide population-based data that would be useful in the interpretation of macular thickness values in persons with diabetes.

- We have shown that macular thickness measurements are increased in moderate or severe DR even when diabetic macular oedema is absent.

- These findings should be considered when designing and interpreting clinical trials evaluating OCT measurements in diabetic persons.

\section{Conflict of interest}

The authors declare no conflict of interest.

\section{Acknowledgements}

This study was funded by the National Medical Research Council (NMRC), NMRC/STaR/0003/2008 and Biomedical Research Council (BMRC), 08/1/35/19/440, Singapore.

\section{Author contributions}

Design of study (CCAS, CYC, REM, RL, PM, TA, TWY); conduct of study (CYC, REM, RL, TYW), statistical analysis (CCAS, WW), preparation of manuscript (CCAS, CYC, REM, RL, WW, PM, TA, TYW). Written informed consent was obtained from each participant and the study conducted adhered to the Declaration of Helsinki. Ethics approval was obtained from the Singapore Eye Research Institute Institutional Review Board.

\section{References}

1 Huang D, Swanson E, Lin C, Schuman JS, Stinson WG, Chang W et al. Optical coherence tomography. Science 1991; 254: 1178-1181.

2 Tangelder G, Van der Heijde R, Polak B, Ringens P. Precision and reliability of retinal thickness measurements in foveal and extrafoveal areas of healthy and diabetic eyes. Invest Ophthalmol Vis Sci 2008; 49: 2627-2634.

3 Eriksson U, Holmstrom G, Alm A, Larsson E. A populationbased study of macular thickness in full-term children assessed with Stratus OCT: normative data and repeatability. Acta Ophthalmol 2009; 87: 714-715.

4 Huynh S, Wang X, Burlutsky G, Rochtchina E, Stapleton F, Mitchell P. Retinal and optic disc findings in adolescence: a population-based OCT study. Invest Ophthalmol Vis Sci 2008; 49: 4328-4335.

5 Duan X, Liang Y, Friedman D, Sun LP, Wong TY, Tao QS et al. Normal macular thickness measurements using optical coherence tomography in healthy eyes of adult Chinese persons: the Handan Eye Study. Ophthalmology 2010; 117: 1585-1594.

6 Asefzadeh B, Fisch B, Parenteau C, Cavallerano A. Macular thickness and systemic markers for diabetes in individuals with no or mild diabetic retinopathy. Clin Experiment Ophthalmol 2008; 36: 455-463.

7 Biallosterski C, van Velthoven M, Michels R, Schlingemann R, DeVries J, Verbraak F. Decreased optical coherence tomography-measured pericentral retinal thickness in patients with diabetes mellitus type 1 with minimal diabetic retinopathy. Br J Ophthalmol 2007; 91: 1135-1138.

8 Bressler N, Edwards A, Antoszyk A, Beck RW, Browning DJ, Ciardella AP et al. Retinal thickness on Stratus optical coherence tomography in people with diabetes and minimal 
or no diabetic retinopathy. Am J Ophthalmol 2008; 145 : 894-901.

9 Wild S, Roglic G, Green A, Sicree R, King H. Global prevalence of diabetes: estimates for the year 2000 and projections for 2030. Diabetes Care 2004; 27: 1047-1053.

10 Goebel W, Franke R. Retinal thickness in diabetic retinopathy: comparison of optical coherence tomography, the retinal thickness analyzer, and fundus photography. Retina 2006; 26: 49-57.

11 Goebel W, Kretzchmar-Gross T. Retinal thickness in diabetic retinopathy: a study using optical coherence tomography (OCT). Retina 2002; 22: 759-767.

12 Lattanzio R, Brancato R, Pierro L, Bandello F, Iaccher B, Fiore $\mathrm{T}$ et al. Macular thickness measured by optical coherence tomography in diabetic patients. Eur J Ophthalmol 2002; 12: 482-487.

13 Massin P, Erginay A, Haouchine B, Mehidi A, Paques M, Gaudric A. Retinal thickness in healthy and diabetic subjects measured using optical coherence tomography mapping software. Eur J Ophthalmol 2002; 12: 102-108.

14 Sanchez-Tocino H, Alvarez-Vidal A, Maldonado M, Moreno-Montanes J, Garcia-Layana A. Retinal thickness study with optical coherence tomography in patients with diabetes. Invest Ophthalmol Vis Sci 2002; 43: 1588-1594.

15 Schaudig U, Glaefke C, Scholz F, Richard G. Optical coherence tomography for retinal thickness measurement in diabetic patients without clinically significant macular oedema. Ophthalmic Surg Lasers 2000; 31: 182-186.

16 Sugimoto M, Sasoh M, Ido M, Wakitani Y, Takahashi C, Uji Y. Detection of early diabetic change with optical coherence tomography in type 2 diabetes mellitus patients without retinopathy. Ophthalmologica 2005; 219: 379-385.

17 Yang C, Cheng C, Lee F, Hsu W, Liu J. Quantitative assessment of retinal thickness in diabetic patients with and without clinically significant macular edema using optical coherence tomography. Acta Ophthalmol Scand 2001; 79: 266-270.

18 Kashani A, Zimmer-Galler I, Shah S, Dustin L, Do DV, Eliott $\mathrm{D}$ et al. Retinal thickness analysis by race, gender, and age using Stratus OCT. Am J Ophthalmol 2010; 149: 496-502.

19 Nilsson M, von Wendt G, Wanger P, Martin L. Early detection of macular changes in patients with diabetes using Rarebit Fovea Test and optical coherence tomography. Br J Ophthalmol 2007; 91: 1596-1598.

20 Lieth E, Gardner T, Barber A, Antonetti D. Retinal neurodegeneration: early pathology in diabetes. Clin Experiment Ophthalmol 2000; 28: 3-8.

21 Lavanya R, Jeganathan V, Zheng Y, Raju P, Cheung N, Tai ES et al. Methodology of the Singapore Indian Chinese Cohort (SICC) eye study: quantifying ethnic variations in the epidemiology of eye diseases in Asians. Ophthalmic Epidemiol 2009; 16: 325-336.

22 Zheng Y, Lavanya R, Wu R, Wong WL, Wang JJ, Mitchell P et al. Prevalence and causes of visual impairment and blindness in an urban indian population The Singapore Indian Eye Study. Ophthalmology 2011; 118(9): 1798-1804.

23 Polito A, Del Borrello M, Isola M, Zemella N, Bandello F. Repeatability and reproducibility of fast macular thickness mapping with stratus optical coherence tomography. Arch Ophthalmol 2005; 123: 1330-1337.

24 Early Treatment Diabetic Retinopathy Study Research Group. Early treatment diabetic retinopathy study design and baseline patient characteristic. ETDRS report number 7. Ophthalmology 1991; 98: 741-756.

25 Diabetic Retinopathy Study Coordinating Center. Diabetic Retinopathy Study: Manual of Operations. MDRSCC: Baltimore, 1972.

26 Early Treatment Diabetic Retinopathy Study Research Group. Grading diabetic retinopathy from stereoscopic color fundus photographs - an extension of the modified Airlie House classification. ETDRS report number 10. Ophthalmology 1991; 98(5 Suppl): 786-806.

27 Wong TY, Cheung N, Tay WT, Wang JJ, Aung T, Saw SM et al. Prevalence and risk factors for diabetic retinopathy: the Singapore Malay Eye Study. Ophthalmology 2008; 115(11): 1869-1875.

28 Pan CW, Wong TY, Lavanya R, Wu RY, Zheng YF, Lin XY et al. Prevalence and risk factors for refractive errors in Indians: the Singapore Indian Eye Study (SINDI). Invest Ophthalmol Vis Sci 2011; 52(6): 3166-3173.

29 Fritsche P, Van der Heijde R, Suttorp-Schulten M, Polak B. Retinal thickness analysis (RTA): an objective method to assess and quantify the retinal thickness in healthy controls and in diabetics without diabetic retinopathy. Retina 2002; 22: 768-771.

30 Giebel S, Menicucci G, McGuire P, Das A. Matrix metalloproteinases in early diabetic retinopathy and their role in alteration of the blood-retinal barrier. Lab Invest 2005; 85: 597-607.

31 Sander B, Larsen M, Engler C, Lund-Andersen H, Parving $\mathrm{H}$. Early changes in diabetic retinopathy: capillary loss and blood-retina barrier permeability in relation to metabolic control. Acta Ophthalmol 1994; 72: 553-559.

32 Hudson C, Flanagan JG, Turner GS, Chen HC, Rawji MH, McLeod D. Exaggerated relative nasal-temporal asymmetry of macular capillary blood flow in patients with clinically significant diabetic macular oedema. Br J Ophthalmol 2005; 89(2): 142-146.

33 Virgili G, Menchini F, Murro V, Peluso E, Rosa F, Casazza G. Optical coherence tomography (OCT) for detection of macular oedema in patients with diabetic retinopathy. Cochrane Database Syst Rev 2011; (7): CD008081.

34 Verma A, Rani P, Raman R, Pal SS, Laxmi G, Gupta M et al. Is neuronal dysfunction an early sign of diabetic retinopathy? Microperimetry and spectral domain optical coherence tomography (SD-OCT) study in individuals with diabetes, but no diabetic retinopathy. Eye 2009; 23: 1824-1830.

35 Pires I, Bernardes R, Lobo C, Soares M, Cunha-Vaz J. Retinal thickness in eyes with mild nonproliferative retinopathy in patients with type 2 diabetes mellitus: comparison of measurements obtained by retinal thickness analysis and optical coherence tomography. Arch Ophthalmol 2002; 120: 1301-1306.

36 Weinberger D, Axer-Siegel R, Landau D, Yassur Y. Retinal thickness variation in the diabetic patient measured by the retinal thickness analyser. Br J Ophthalmol 1998; 82: 1003-1006.

37 Yasukawa T, Kiryu J, Tsujikawa A, Dong J, Suzuma I, Takagi $\mathrm{H}$ et al. Quantitative analysis of foveal retinal thickness in diabetic retinopathy with the scanning retinal thickness analyzer. Retina 1998; 18: 150-155.

38 Kelty P, Payne J, Trivedi R, Kelty J, Bowie E, Burger B. Macular thickness assessment in healthy eyes based on ethnicity using Stratus OCT optical coherence tomography. Invest Ophthalmol Vis Sci 2008; 49: 2668-2672. 
39 Wong A, Chan C, Hui S. Relationship of gender, body mass index, and axial length with central retinal thickness using optical coherence tomography. Eye 2005; 19: 292-297.

40 Lam D, Leung K, Mohamed S, Chan WM, Palanivelu MS, Cheung CY et al. Regional variations in the relationship between macular thickness measurements and myopia. Invest Ophthalmol Vis Sci 2007; 48: 376-382.

41 Wu P, Chen Y, Chen C, Chen YH, Shin SJ, Yang HJ et al. Assessment of macular retinal thickness and volume in normal eyes and highly myopic eyes with third-generation optical coherence tomography. Eye 2008; 22: 551-555.

42 Neuville JM, Bronson-Castain K, Bearse Jr MA, Nq JS, Harrison WW, Schneck ME et al. OCT reveals regional differences in macular thickness with age. Optom Vis Sci 2009; 86(7): E810-E816.

43 Yeung L, Sun CC, Ku WC, Chuang LH, Chen CH, Huang BY et al. Associations between chronic glycosylated haemoglobin $(\mathrm{HbA} 1 \mathrm{c})$ level and macular volume in diabetes patients without macular oedema. Acta Ophthalmol 2010; 88(7): 753-758.

44 Chou TH, Wu PC, Kuo JZ, Lai CH, Kuo CN. Relationship of diabetic macular oedema with glycosylated haemoglobin. Eye 2009; 23(6): 1360-1363.

45 Asefzadeh B, Fisch BM, Parenteau CE, Cavallerano AA. Macular thickness and systemic markers for diabetes in individuals with no or mild diabetic retinopathy. Clin Experiment Ophthalmol 2008; 36(5): 455-463.
46 Verma A, Rani PK, Raman R, Pal SS, Laxmi G, Gupta M et al. Is neuronal dysfunction an early sign of diabetic retinopathy? Microperimetry and spectral domain optical coherence tomography (SD-OCT) study in individuals with diabetes, but no diabetic retinopathy. Eye 2009; 23(9): 1824-1830.

47 Brown JC, Solomon SD, Bressler SB, Schachat AP, DiBernardo C, Bressler NM. Detection of diabetic foveal edema: contact lens biomicroscopy compared with optical coherence tomography. Arch Ophthalmol 2004; 122(3): 330-335.

48 Bhavsar KV, Subramanian ML. Risk factors for progression of subclinical diabetic macular oedema. Br J Ophthalmol 2011; 95(5): 671-674.

49 Browning DJ, Fraser CM. The predictive value of patient and eye characteristics on the course of subclinical diabetic macular edema. Am J Ophthalmol 2008; 145(1): 149-154.

50 Ganapathy PS, Roon P, Moister TK, Mysona B, Smith SB. Diabetes accelerates retinal neuronal cell death in a mouse model of endogenous hyperhomocysteinemia. Ophthalmol Eye Dis 2009; 1: 3-11.

51 Greenfield D, Bagga H, Knighton R. Macular thickness changes in glaucomatous optic neuropathy detected using optical coherence tomography. Arch Ophthalmol 2003; 121: $41-46$.

52 Leung C, Chan W, Yung W, Ng AC, Woo J, Tsang MK et al. Comparison of macular and peripapillary measurements for the detection of glaucoma: an optical coherence tomography study. Ophthalmology 2005; 112: 391-400. 